\title{
A New Approach to Carbonate Alkalinity
}

\author{
Bogusław Pilarski1, Anna M. Michałowska-Kaczmarczyk², Agustin G. Asuero ${ }^{3}$, \\ Agnieszka Dobkowska1, Monika Lewandowska1, Tadeusz Michałowski4* \\ ${ }^{1}$ CERKO Sp. z o.o. Sp. K., Gdynia, Poland \\ ${ }^{2}$ Department of Oncology, The University Hospital in Cracow, Cracow, Poland \\ ${ }^{3}$ Department of Analytical Chemistry, The University of Seville, Seville, Spain \\ ${ }^{4}$ Faculty of Engineering and Chemical Technology, Cracow University of Technology, Cracow, Poland \\ Email: "michalot@o2.pl
}

Received 25 April 2014; revised 26 May 2014; accepted 8 June 2014

Copyright (C) 2014 by authors and Scientific Research Publishing Inc.

This work is licensed under the Creative Commons Attribution International License (CC BY).

http://creativecommons.org/licenses/by/4.0/

\section{Abstract}

The article provides experimental data applied to the determination of carbonate alkalinity (CAM) according to modified Gran II functions. CAM is related to the mixtures $\mathrm{NaHCO}_{3}+\mathrm{Na}_{2} \mathrm{CO}_{3}$ and $\mathrm{Na}_{2} \mathrm{CO}_{3}+\mathrm{NaOH}$. In addition to the determination of equivalence volumes, one of the main novelties of the proposed method is the possibility of determining the activity coefficient of hydrogen ions $(\gamma)$. Moreover, CAM can be used to calculate the dissociation constants $\left(K_{1}, K_{2}\right)$ for carbonic acid and the ionic product of water $\left(\mathrm{K}_{\mathrm{W}}\right)$ from a single $\mathrm{pH}$ titration curve. The parameters of the related functions are calculated according to the least squares method.

\section{Keywords}

Carbonate Alkalinity, pH Titration, Mathematical Modelling

\section{Introduction}

In the papers [1] [2] published recently, the new approaches to the measurement of total alkalinity (TAL) and carbonate alkalinity (CAM) were presented. In particular, $\mathrm{CAM}$ refers to titrimetric analysis of two systems $\left(\mathrm{V}_{0}\right.$ $\mathrm{mL}): \mathrm{NaHCO}_{3}\left(\mathrm{C}_{01}\right)+\mathrm{Na}_{2} \mathrm{CO}_{3}\left(\mathrm{C}_{02}\right)$ (System I), and $\mathrm{Na}_{2} \mathrm{CO}_{3}\left(\mathrm{C}_{02}\right)+\mathrm{NaOH}\left(\mathrm{C}_{\mathrm{b}}\right)$ (System II). The results $\left\{\left(\mathrm{V}_{\mathrm{j}}\right.\right.$, $\left.\mathrm{pH}_{\mathrm{j}}\right) \mid \mathrm{j}=1, \ldots, \mathrm{N}$ \} obtained from $\mathrm{pH}$ titration of the corresponding systems with $\mathrm{C} \mathrm{mol} / \mathrm{L} \mathrm{HCl}$, undertaken under isothermal conditions, are presented according to a modified Gran II method. The CAM concept is fully compatible with the TAL concept, in which other species with acid-base properties are also included.

The equivalence volumes $\mathrm{V}_{\text {eqi }}(\mathrm{i}=1,2,3)$ referring to the corresponding components in Systems I and II are involved in the following relationships:

\footnotetext{
${ }^{*}$ Corresponding author.
}

How to cite this paper: Pilarski, B., Michałowska-Kaczmarczyk, A.M., Asuero, A.G., Dobkowska, A., Lewandowska, M. and Michałowski, T. (2014) A New Approach to Carbonate Alkalinity. Journal of Analytical Sciences, Methods and Instrumentation, 4, 62-69. http://dx.doi.org/10.4236/jasmi.2014.42009 


$$
\begin{gathered}
\mathrm{C} \cdot \mathrm{V}_{e q 1}=\mathrm{C}_{01} \cdot \mathrm{V}_{0}, \mathrm{C} \cdot \mathrm{V}_{e q 2}=2 \mathrm{C}_{02} \cdot \mathrm{V}_{0} \text { for System I and } \\
\mathrm{C} \cdot \mathrm{V}_{e q 2}=2 \mathrm{C}_{02} \cdot \mathrm{V}_{0}, \mathrm{C} \cdot \mathrm{V}_{e q 3}=\mathrm{C}_{b} \cdot \mathrm{V}_{0} \text { for System II }
\end{gathered}
$$

Subsequently, the carbonate alkalinities (CAM, mmol/L) are calculated from the formulae: $\mathrm{CAM}(\mathrm{I})=10^{3} \cdot\left(\mathrm{C}_{01}\right.$ $\left.+2 \mathrm{C}_{02}\right)$ or $\mathrm{CAM}(\mathrm{II})=10^{3} \cdot\left(2 \mathrm{C}_{02}+\mathrm{C}_{\mathrm{b}}\right)$, i.e.,

$$
\begin{aligned}
& C A M(\mathrm{I})=10^{3} \cdot C\left(\mathrm{~V}_{e q 1}+\mathrm{V}_{e q 2}\right) / \mathrm{V}_{0} \text { for System I } \\
& \operatorname{CAM}(\mathrm{II})=10^{3} \cdot C\left(\mathrm{~V}_{\text {eq } 2}+\mathrm{V}_{\text {eq3 }}\right) / \mathrm{V}_{0} \text { for System II }
\end{aligned}
$$

The present paper provides a new approach to the problem in question. This approach enables equivalence volumes $\left(\mathrm{V}_{\text {eqi }}\right)$ to be calculated and the following physicochemical data to be evaluated: dissociation constants ( $\mathrm{K}_{1}$ and $\mathrm{K}_{2}$ ) of $\mathrm{H}_{2} \mathrm{CO}_{3}$, the ionic product of water $\left(\mathrm{K}_{\mathrm{W}}\right)$, and the activity coefficient $(\gamma)$ of hydrogen ions-not only in aqueous media, but also in binary-solvent systems [3]. The functions derived for this purpose have a form similar to those ascribed to Gran II method. The validity of the models proposed was confirmed experimentally by $\mathrm{pH}$ titration of synthetic samples referring to Systems I and II.

\section{The Gran-Type Functions}

The Gran functions applicable for determination of CAM(I) (Equation (3)) and CAM(II) (Equation (4)) are detailed in Table 1 [2]. The notations applied there are as follows: $\mathrm{ph}=-\operatorname{logh}, \mathrm{h}=\gamma \cdot\left[\mathrm{H}^{+}\right]$- activity, and $\gamma$ - the activity coefficient of hydrogen ions; $K_{1}^{*}=\gamma \cdot K_{1}, \quad K_{2}^{*}=\gamma \cdot K_{2}, \quad K_{W}^{*}=\gamma \cdot K_{W}$ - hybrid values for $\mathrm{K}_{1}=$ $\left[\mathrm{H}^{+}\right]\left[\mathrm{HCO}_{3}^{-}\right] /\left[\mathrm{H}_{2} \mathrm{CO}_{3}\right], \mathrm{K}_{2}=\left[\mathrm{H}^{+}\right]\left[\mathrm{CO}_{3}^{2-}\right] /\left[\mathrm{HCO}_{3}^{-}\right]$, and $\mathrm{K}_{\mathrm{W}}=\left[\mathrm{H}^{+}\right]\left[\mathrm{OH}^{-}\right]$. The $\mathrm{pH}$ intervals, in which the corresponding Gran-like functions are valid, are denoted by b, c, d for System I, and by a, b, c, d for System II.

Interval a is not included in System I in Table 1; simply because the data $\left\{\left(\mathrm{V}_{\mathrm{j}}, \mathrm{pH}_{\mathrm{j}}\right) \mid \mathrm{j}=1, \ldots, \mathrm{N}\right\}$ do not cover this $\mathrm{pH}$ range in System I. Regarding System II, the experimental points may not cover interval a at lower $\mathrm{C}_{\mathrm{b}}$ values.

The case where $\mathrm{V}_{0} \mathrm{~mL}$ of $\mathrm{C}_{02} \mathrm{~mol} / \mathrm{L} \mathrm{Na} \mathrm{CO}_{3}$ is titrated with $\mathrm{V} \mathrm{mL}$ of $\mathrm{C} \mathrm{mol} / \mathrm{L} \mathrm{HCl}$ is a particular case of System I (at $\left.\mathrm{C}_{01}=0\right)$ or System II $\left(a t C_{b}=0\right)$. Note that the formulae related to Systems I and II are identical in $\mathrm{pH}$ intervals $d$ and c (see Table 1), but the formulae are different in interval b. However, at $\mathrm{V}_{\mathrm{b}}=\mathrm{V}_{\text {eq1 }}=0$ and $\mathrm{V}_{\mathrm{a}}$ $=\mathrm{V}_{\mathrm{eq} 3}=0$, both formulae are simplified into the following form:

$$
V \cdot 10^{p h}=\left(K_{2}^{*}\right)^{-1} \cdot\left(V_{\text {eq2 }} / 2-V\right)
$$

In the data handling step referring to simulated or experimental data $\left\{\left(\mathrm{V}_{\mathrm{j}}, \mathrm{pH}_{\mathrm{j}}\right) \mid \mathrm{j}=1, \ldots, \mathrm{N}\right\}$, the Gran functions are applied to the sequences of $\mathrm{pH}$ intervals, such as those specified in Table 1 . The use of other possible sequences is not advised.

The parameters:

- $\mathrm{V}_{\mathrm{eq} 1}, \mathrm{~V}_{\mathrm{eq} 2}, \mathrm{~K}_{1}{ }^{*}, \mathrm{~K}_{2}{ }^{*}$ and $\gamma$ (and then $\mathrm{K}_{1}=\mathrm{K}_{1}{ }^{*} / \gamma, \mathrm{K}_{2}=\mathrm{K}_{2}{ }^{*} / \gamma$ ) for the modified Gran functions referring to System I, or

- $\mathrm{V}_{\mathrm{eq} 2}, \mathrm{~V}_{\mathrm{eq} 3}, \mathrm{~K}_{1}{ }^{*}, \mathrm{~K}_{2}{ }^{*}$ and $\gamma$ (and then $\mathrm{K}_{1}=\mathrm{K}_{1}{ }^{*} / \gamma, \mathrm{K}_{2}=\mathrm{K}_{2}{ }^{*} / \gamma$ ) for the modified Gran functions referring to System II,

can be found according to the least squares method (LSM) [4] [5] applied to the experimental points:

$$
\left\{\left(V_{j}^{x}, p h_{j}^{x}\right) \mid j=1, \cdots, N_{x}\right\}
$$

referring separately to particular $\mathrm{x}$ intervals: $\mathrm{x}=\mathrm{b}, \mathrm{c}, \mathrm{d}$ (System I), or $\mathrm{x}=\mathrm{a}, \mathrm{b}, \mathrm{c}, \mathrm{d}$ (System II) in Table 1, with the set of $\mathrm{N}_{\mathrm{x}}$ points, related to the $\mathrm{x}$-th $\mathrm{pH}$ interval. It is worth noting that the ph, referring to activity $\mathrm{h}$ of $\mathrm{H}^{+}$ ions, is measured in experimental titrations. The $\mathrm{ph}=-\operatorname{logh}$ as variable (not $\mathrm{pH}=-\log \left[\mathrm{H}^{+}\right]$) is involved in all relationships specified in Table 1.

\section{Calculation Procedure}

The functions in Table 1 can be presented in a unified form of the linear regression equation: 
Table 1. The Gran functions related to Systems I and II.

\begin{tabular}{|c|c|c|c|}
\hline \multirow{2}{*}{ No. } & \multirow{2}{*}{$\mathrm{pH}$ interval } & \multicolumn{2}{|c|}{ Gran type functions } \\
\hline & & System I & System II \\
\hline a & $\mathrm{pH}>\mathrm{pK}_{2}+\Delta$ & - & $\left(V_{0}+V\right) \cdot 10^{p h}=C / K_{w}^{*} \cdot\left(V_{a}-V\right)$ \\
\hline $\mathrm{b}$ & $\mathrm{pK}_{2}-\Delta<\mathrm{pH} \approx \mathrm{pK}_{2}$ & $\left(V_{b}+V\right) \cdot 10^{p h}=\left(K_{2}^{*}\right)^{-1} \cdot\left(V_{c}-V\right)$ & $\left(V-V_{a}\right) \cdot 10^{p h}=\left(K_{2}^{*}\right)^{-1} \cdot\left(V_{b}-V\right)$ \\
\hline c & $\mathrm{pK}_{1}-\Delta \leq \mathrm{pH} \leq \mathrm{pK}_{1}+\Delta$ & $\left(V_{d}-V\right) \cdot 10^{-p h}=K_{1}^{*} \cdot\left(V-V_{c}\right)$ & $\left(V_{d}-V\right) \cdot 10^{-p h}=K_{1}^{*} \cdot(V-V)_{c}$ \\
\hline d & $\mathrm{pH}<\mathrm{pK}_{1}-\Delta$ & $\left(V_{0}+V\right) \cdot 10^{-p h}=\gamma \cdot C \cdot\left(V-V_{d}\right)$ & $\left(V_{0}+V\right) \cdot 10^{-p h}=\gamma \cdot C \cdot\left(V-V_{d}\right)$ \\
\hline & Sequence of operations & $\mathrm{d} \rightarrow \mathrm{c}$ and $\mathrm{b}$ & $\mathrm{d} \rightarrow \mathrm{c}$ and $\mathrm{b}, \mathrm{a}$ \\
\hline & Relationships & $\begin{array}{c}\mathrm{V}_{\mathrm{d}}=\mathrm{V}_{\text {eq1 } 1}+\mathrm{V}_{\mathrm{eq} 2} \\
\mathrm{~V}_{\mathrm{c}}=\mathrm{V}_{\text {eq } 2} / 2 \\
\mathrm{~V}_{\mathrm{b}}=\mathrm{V}_{\text {eq1 } 1}\end{array}$ & $\begin{array}{c}\mathrm{V}_{\mathrm{d}}=\mathrm{V}_{\mathrm{eq} 2}+\mathrm{V}_{\mathrm{eq} 3} \\
\mathrm{~V}_{\mathrm{c}}=\mathrm{V}_{\mathrm{b}}=\mathrm{V}_{\mathrm{eq} 2} / 2+\mathrm{V}_{\mathrm{eq} 3} \\
\mathrm{~V}_{\mathrm{a}}=\mathrm{V}_{\mathrm{eq} 3}\end{array}$ \\
\hline
\end{tabular}

$$
y_{j}^{x}=A_{x} \cdot V_{j}^{x}+B_{x}+\varepsilon_{j}^{x} \quad\left(j=1, \cdots, N_{x} ; x=a, b, c, d\right)
$$

Subsequently, applying LSM to the sum of squares

$$
S S(x)=\sum_{j=1}^{N_{x}}\left(\varepsilon_{j}^{x}\right)^{2}
$$

where $j$ refers to the points $\left\{\left(V_{j}^{x}, p h_{j}^{x}\right) \mid j=1, \cdots, N_{x}\right\}$ related to x-th subset $(\mathrm{x}=\mathrm{a}, \mathrm{b}, \mathrm{c}, \mathrm{d})$, we obtain the formulae:

$$
A_{x}=\frac{N_{x} \cdot \sum_{x} V_{j}^{x} y_{j}^{x}-\sum_{x} V_{j}^{x} \cdot \sum_{x} y_{j}^{x}}{N_{x} \cdot \sum_{x}\left(V_{j}^{x}\right)^{2}-\left(\sum_{x} V_{j}^{x}\right)^{2}}, \quad B_{x}=\frac{\sum_{x}\left(V_{j}^{x}\right)^{2} \cdot \sum_{x} y_{j}^{x}-\sum_{x} V_{j}^{x} \cdot \sum_{x} V_{j}^{x} y_{j}^{x}}{N_{x} \cdot \sum_{x}\left(V_{j}^{x}\right)^{2}-\left(\sum_{x} V_{j}^{x}\right)^{2}}
$$

where the sum $\Sigma_{x}$ covers the points taken from the x-th interval, $V_{j}^{x}$ is the $\mathrm{j}$-th $\mathrm{V}$-value taken from the x-th interval.

As stated above, calculation of the parameters is possible in a defined sequence of operations. For example, the sequence $d \rightarrow c$ applied in Table 1 for System I means that $V_{d}$ value, obtained according to LSM for the data $\left\{\left(V_{j}^{d}, p h_{j}^{d}\right) \mid j=1, \cdots, N_{d}\right\}$ composing the subset of the points taken from interval d (Figure 1 ), is inserted on the left side of the relationship referring to interval c and LSM is applied to the data

$\left\{\left(V_{j}^{c}, p h_{j}^{c}\right) \mid j=1, \cdots, N_{c}\right\}$ taken from interval c; in this way, the $\mathrm{V}_{\mathrm{c}}$ value is obtained. From $\mathrm{V}_{\mathrm{d}}$ and $\mathrm{V}_{\mathrm{c}}$, one can calculate:

$$
\begin{gathered}
V_{e q 1}=V_{d}-2 V_{c}=2 \cdot \frac{B_{c}}{A_{c}}-\frac{B_{d}}{A_{d}} \text { and } V_{e q 2}=2 \cdot \frac{B_{c}}{A_{c}} \quad \text { for System I (Table 1) } \\
V_{e q 2}=2 \cdot\left(V_{d}-V_{c}\right)=2 \cdot\left(\frac{B_{c}}{A_{c}}-\frac{B_{d}}{A_{d}}\right) \text { and } V_{e q 3}=\frac{B_{d}}{A_{b}}-2 \cdot \frac{B_{c}}{A_{c}} \quad \text { for System II (Table 1) }
\end{gathered}
$$

Moreover, we obtain:

$$
\gamma=\frac{A_{d}}{C}, p K_{1}^{*}=-\log A_{c}, p K_{1}=\log \frac{A_{d}}{A_{c}}-\log C \text { for Systems I and II (Table 1) }
$$

From Table 1, System I, no. b, for the point $\left(V_{j}^{b}, p h_{j}^{b}\right)$ we get 


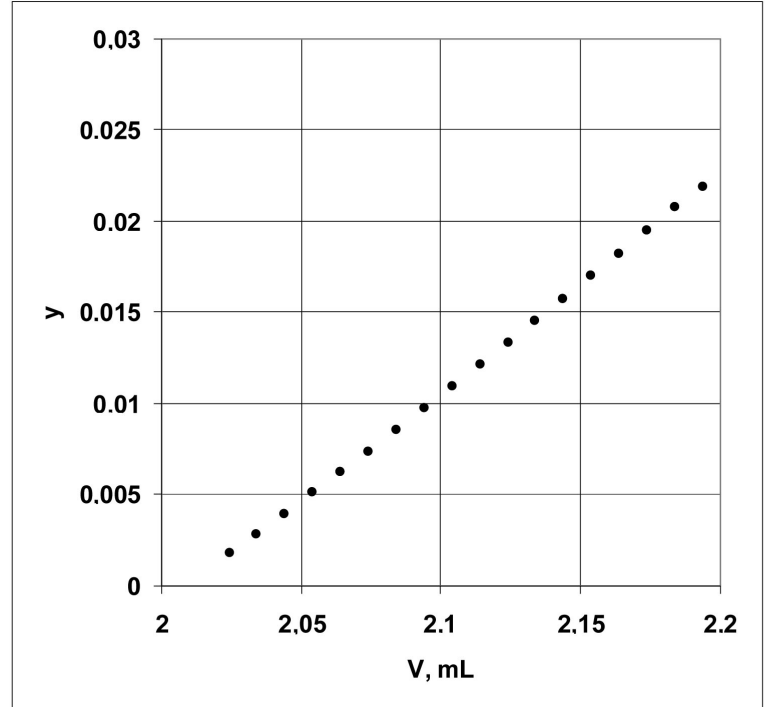

(a)

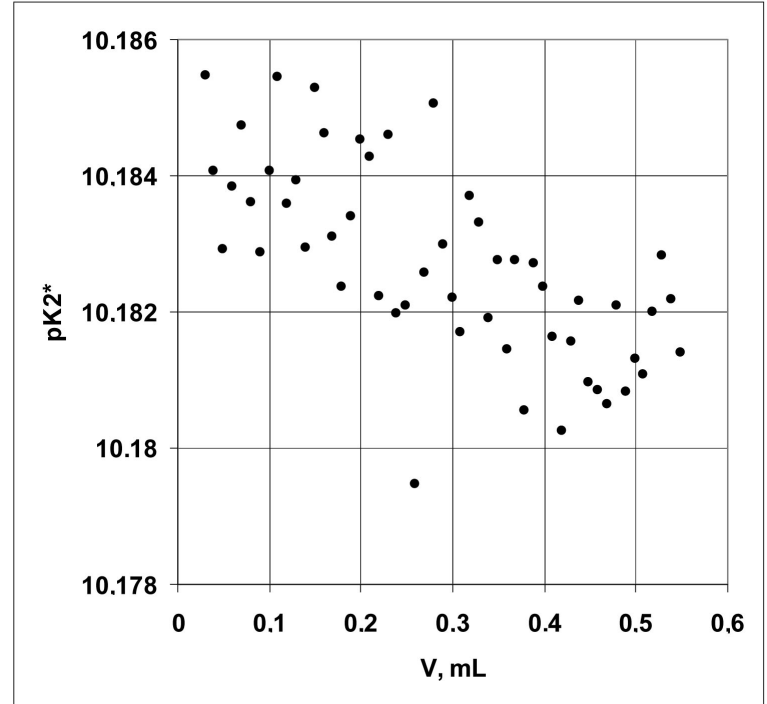

(c)

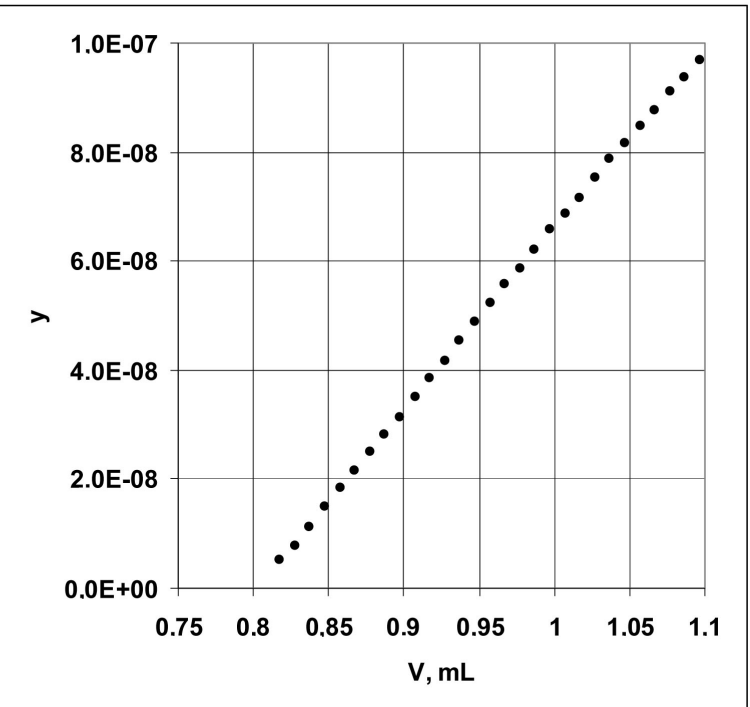

(b)

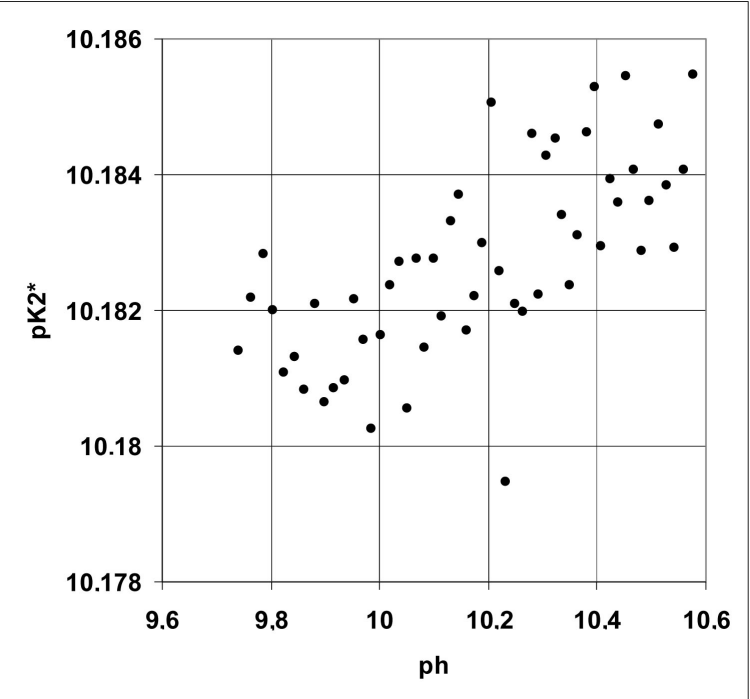

(d)

Figure 1. Plots related to $\mathrm{NaHCO}_{3}\left(\mathrm{C}_{1}\right)+\mathrm{Na}_{2} \mathrm{CO}_{3}\left(\mathrm{C}_{2}\right)$ system: y (Table 1, System I) vs V relationships in (a) d interval; (b) c interval; (c) $p K_{2}^{*}$ vs. V, and (d) $p K_{2}^{*}$ vs. ph plots.

$$
p K_{2 j}^{*}=p h_{j}^{b}+\log \frac{V_{b}+V_{j}^{b}}{V_{c}-V_{j}^{b}}=p h_{j}^{b}+\log \frac{V_{e q 1}+V_{j}^{b}}{V_{e q 2} / 2-V_{j}^{b}}
$$

where $\mathrm{V}_{\mathrm{eq} 1}$ and $\mathrm{V}_{\mathrm{eq} 2}$ are expressed by Equation (1). Similarly, from Table 1, System II, no. b and a, we get

$$
\begin{gathered}
p K_{2 j}^{*}=p h_{j}^{b}+\log \frac{V_{j}^{b}-V_{a}}{V_{b}-V_{j}^{b}}=p h_{j}^{b}+\log \frac{V_{j}^{b}-V_{e q 3}}{V_{e q 2} / 2+V_{e q 3}-V_{j}^{b}} \\
p K_{W j}^{*}=p h_{j}^{a}+\log \frac{V_{0}+V_{j}^{a}}{V_{a}-V_{j}^{a}}-\log C=p h_{j}^{a}+\log \frac{V_{0}+V_{j}^{a}}{V_{e q 3}-V_{j}^{a}}-\log C
\end{gathered}
$$

respectively, where $\mathrm{V}_{\mathrm{eq} 2}$ and $\mathrm{V}_{\mathrm{eq}}$ are expressed by Equation (2). On the basis of Equation (5), we obtain the relationship: 


$$
p K_{2 j}^{*}=p h_{j}^{b}+\log \frac{V_{j}^{b}}{V_{e q 2} / 2-V_{j}^{b}}
$$

We then calculate:

$$
\begin{gathered}
p K_{2}^{*}=\frac{1}{N_{b}} \cdot \sum_{j=1}^{N_{b}} p K_{2 j}^{*} \text { and } p K_{2}=p K_{2}^{*}+\log \gamma \\
p K_{W}^{*}=\frac{1}{N_{a}} \cdot \sum_{j=1}^{N_{a}} p K_{W j}^{*} \text { and } p K_{W}=p K_{W}^{*}+\log \gamma
\end{gathered}
$$

and

$$
p K_{1}=p K_{1}^{*}+\log \gamma
$$

where $\gamma$ is defined in Equation (11). The nearly constant ionic strength value, required during the titration, can be secured by the addition of a basal electrolyte on the stage of $\mathrm{D}$ and $\mathrm{T}$ preparation.

As revealed from Equations (3), (4), it is necessary to know the sum of equivalence volumes: $V_{\text {eq1 }}+V_{\text {eq2 }}$ or $\mathrm{V}_{\text {eq2 }}+\mathrm{V}_{\text {eq3 }}$, to calculate CAM(I) or CAM(II) value. However, determination of $\mathrm{V}_{\text {eqi }}$ values ( $\mathrm{i}=1,2$ or 2, 3) from a single $\mathrm{pH}$ titration curve is also possible.

\section{Experimental Part}

\subsection{Apparatus and Solutions}

The $\mathrm{pH}$ titrations were carried out in a $30 \mathrm{~mL}$ thermostated, self-made measuring cell, equipped with magnetic stirrer and PT 1000 temperature sensor. The $\mathrm{pH}$ measurements and titrations were taken at $22^{\circ} \mathrm{C}$ with a Cerko Lab System microtitrator, equipped with $5 \mathrm{~mL}$ syringe pump, 3-way valve, and $\mathrm{pH}$ electrode (Hydromet, type ERH-13-6). The electrode was standardized with aqueous standard buffers of $\mathrm{pH} 5.00,7.00$ and 10.00, purchased from the Chempur Company. When not in use, the electrode was stored in $3 \mathrm{~mol} / \mathrm{L} \mathrm{KCl}$ solution. Titrant was added into $\mathrm{V}_{0}=4.00 \mathrm{~mL}$ of D stepwise, in aliquots of $0.01 \mathrm{~mL}$, with 6-8-sec. pauses, and the experimental points $\left\{\left(V_{j}, p h_{j}\right) \mid j=1, \cdots, N\right\}$ were recorded.

The reagents: $\mathrm{HCl}, \mathrm{Na}_{2} \mathrm{CO}_{3}, \mathrm{NaHCO}_{3}, \mathrm{NaOH}$ of p.a. grade, purchased from Chempur Company, were used for the preparation of stock and diluted solutions in doubly distilled (freshly prepared, with conductivity of approx. $0.18 \mu \mathrm{S} / \mathrm{cm}$ ) water. Stock solution of hydrochloric acid $(\mathrm{HCl})$ as $\mathrm{T}$, was standardized against $\mathrm{Na}_{2} \mathrm{CO}_{3}$, obtained after prior calcination $\left(220^{\circ} \mathrm{C}, 5 \mathrm{hrs}\right)$ of commercial disodium carbonate. The $\mathrm{NaOH}$ solution was standardized against potassium hydrogen phthalate (p.a., from Merck). Methanol (p.a. grade, 99.5\%, supplied by POCH S.A.) was applied for titrations made in binary-solvent media.

Stock titrands were prepared by dilution of weighed portions of $\mathrm{Na}_{2} \mathrm{CO}_{3}$ and $\mathrm{NaHCO}_{3}$ in water, or by addition of a weighed portion of $\mathrm{Na}_{2} \mathrm{CO}_{3}$ into a standardized $\mathrm{NaOH}$ solution. In other titrations, mixed solvent was prepared from appropriate volumes of water and $\mathrm{CH}_{3} \mathrm{OH}$, and cooled before preparation of $\mathrm{HCl}$ and $\mathrm{Na}_{2} \mathrm{CO}_{3}$ solutions. The $\mathrm{HCl}$ solution $\left(10 \% \mathrm{v} / \mathrm{v} \mathrm{CH}_{3} \mathrm{OH}\right)$ was standardized as described previously. Concentrations of $\mathrm{HCl}$, $\mathrm{NaHCO}_{3}, \mathrm{Na}_{2} \mathrm{CO}_{3}$ and $\mathrm{NaOH}$ in the corresponding solutions are specified below.

\subsection{Results and Discussion}

The approach was applied first to the results of titrations of Systems I and II, with HCl solution as the titrant, T. Titration in System I was carried out at pre-assumed values $\left(\mathrm{V}_{0}, \mathrm{C}_{01}, \mathrm{C}_{02}, \mathrm{C}\right)=(4.000,0.01012,0.02011$, $0.10078) ; \mathrm{V}_{\text {eq1 }}=0.01012 \cdot 4 / 0.10078=0.4017 ; \mathrm{V}_{\text {eq2 }}=2 \cdot 0.02011 \cdot 4 / 0.10078=1.5963$. The results of exemplary titration are graphically presented in Figure 1. The data obtained for $\mathrm{V}_{\mathrm{d}}=2.0122, \mathrm{~V}_{\mathrm{c}}=0.8017$ (Figure 1(a), Figure 1(b)) are in good agreement with the expected values: 1.9980 and 0.7982 (see Table 2). Moreover, we get here: $\gamma=0.9283$ and $p K_{1}^{*}=6.379$. The $\mathrm{pK}_{2 \mathrm{j}}{ }^{*}$ values, calculated on the basis of Equation (13), are plotted in Figure 1(c), Figure 1(d), with V and ph as the variables on the abscissa, respectively. Some discrepancies in $\mathrm{V}_{\text {eq1 }}$ value can result from the poor knowledge of $\mathrm{NaHCO}_{3}$ concentration, which is not a primary standard.

Titration in System II was carried out at pre-assumed values $\left(\mathrm{V}_{0}, \mathrm{C}_{02}, \mathrm{C}_{\mathrm{b}}, \mathrm{C}\right)=(4.000,0.0200,0.0209$, 
0.10078). The results obtained from repeated titrations are detailed in Table $3 ; 2 \cdot 0.0200 \cdot 4 / 0.10078=1.5876$ and $0.0209 \cdot 4 / 0.10078=0.08295$ are the expected values for $V_{\text {eq2 }}$ and $V_{\text {eq3 }}$, respectively. Exemplary data are plotted in Figure 2. As can be seen, the sum $V_{d}=V_{\text {eq2 }}+V_{\text {eq3 } 3}$ is very well reproducible in repeated titrations and is in good agreement with the expected value of 2.4171 (Figure 2(a)). The values for $\mathrm{V}_{\text {eq2 }}$ are slightly smaller than 1.5876 , while the values for $\mathrm{V}_{\text {eq3 }}$ are slightly greater than 0.08295 . The repeatability of values for $\gamma$ and $p K_{1}^{*}$ is lower. The $p K_{w j}^{*}$ (Figure 2(c)) and $p K_{2 j}^{*}$ (Figure 2(d)) values vary regularly (not stochastically) from point-to-point, although the range of ph values covered by the points close to $\mathrm{ph} \approx \mathrm{pK}_{2}=10.1$ is narrow (but in a wider $\mathrm{pK}$ range than in Figure 1(c), Figure 1(d)); also $p K_{1}^{*}$ (and $\mathrm{pK}_{1}=p K_{1}^{*}+\log \gamma$ values are close to 6.3). The $p K_{W j}^{*}$ values are distinctly higher than 14.0 ; this may be ascribed to the non-linear characteristics of the glass electrode in alkaline media. Smaller $p K_{W j}^{*}$ values at lower ph support this opinion.

Another option for System II is also possible a priori and starts from equation a in Table 1 (System II) and finds $\mathrm{V}_{\mathrm{a}}\left(=\mathrm{V}_{\text {eq3 } 3}\right)$ and $K_{W}^{*}$ on the basis of the points $\left\{\left(V_{j}^{a}, p h_{j}^{a}\right) \mid j=1, \cdots, N_{a}\right\}$. The $\mathrm{V}_{\mathrm{a}}$ value is then inserted in equation $\mathrm{b}$ in Table 1 (System II) and $\mathrm{V}_{\mathrm{b}}\left(=\mathrm{V}_{\text {eq2 } 2} / 2+\mathrm{V}_{\text {eq } 3}\right)$ and $K_{2}^{*}$ values are determined on the basis of the

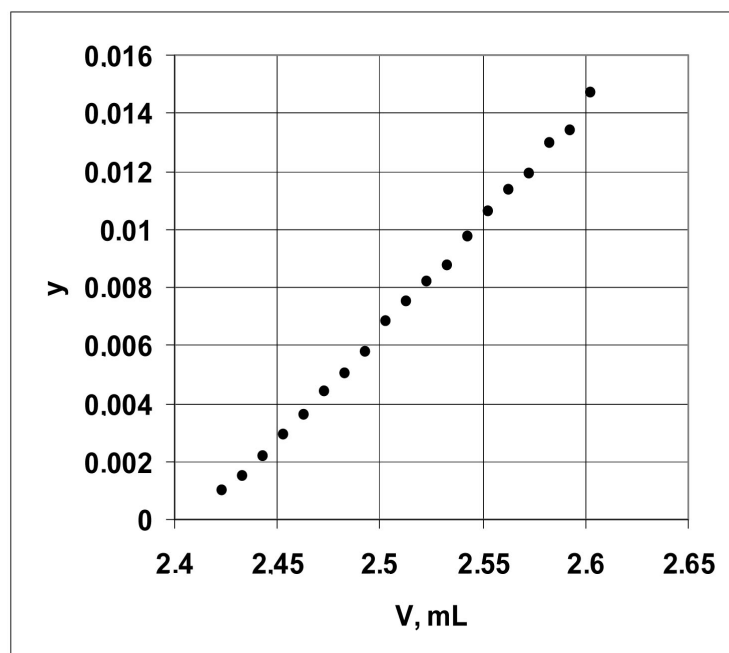

(a)

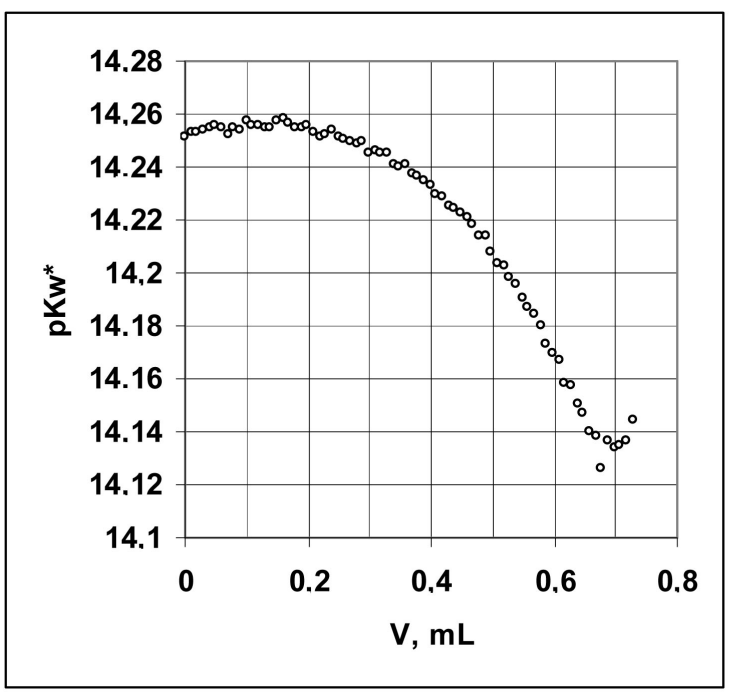

(c)

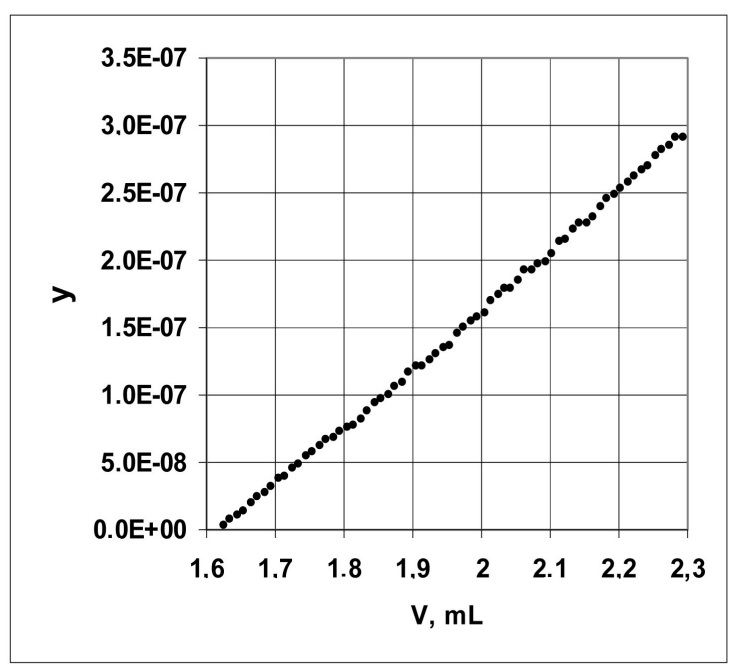

(b)

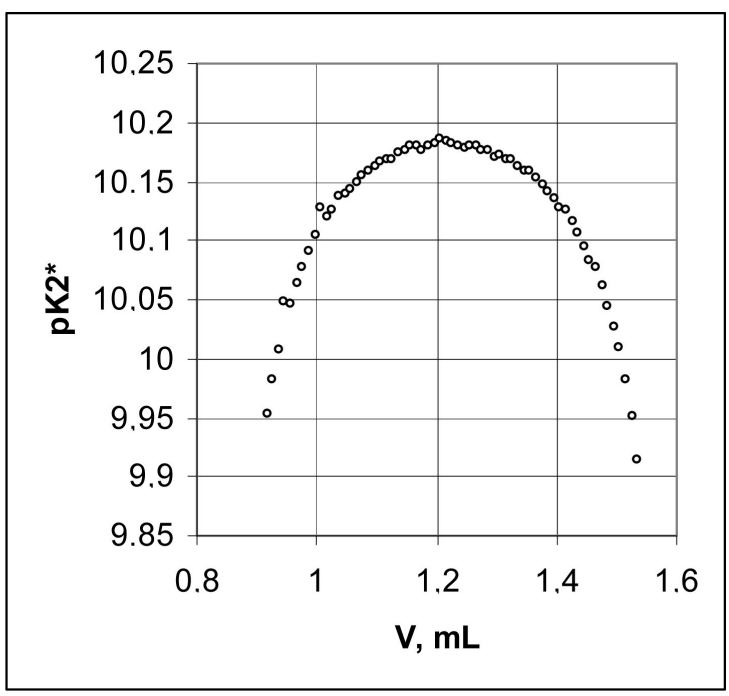

(d)

Figure 2. Plots related to $\mathrm{Na}_{2} \mathrm{CO}_{3}\left(\mathrm{C}_{2}\right)+\mathrm{NaOH}\left(\mathrm{C}_{\mathrm{b}}\right)$ system: y (Table 3) vs. V relationships in (a) d interval; (b) c interval; (c) $p K_{W}^{*} \quad$ vs. V, (d) $p K_{2}^{*}$ vs. V plots. 
points $\left\{\left(V_{j}^{b}, p h_{j}^{b}\right) \mid j=1, \cdots, N_{b}\right\}$. The $\mathrm{V}_{\text {eq2 }}\left(=2\left(\mathrm{~V}_{\mathrm{b}}-\mathrm{V}_{\mathrm{a}}\right)\right)$ and $\mathrm{V}_{\text {eq3 }}$ values can be compared with those obtained on the basis of the experimental points in intervals $d$ and $c$. This procedure could be regarded as a kind of internal validation of the results. However, it should be borne in mind that the results of ph measurements obtained in alkaline media could be loaded by systematic error resulting from the alkaline error of the glass electrode. The errors involved with ph measurements in the a range affect the $\mathrm{V}_{\mathrm{a}}$ value, subsequently applied in the $(\mathrm{V}-$ $\left.\mathrm{V}_{\mathrm{a}}\right) \cdot 10^{\mathrm{ph}}$ vs. $\mathrm{V}$ relationship related to interval $\mathrm{b}$; an improper $\mathrm{V}_{\mathrm{a}}$ value causes this relationship to be a nonlinear one. Therefore, it is advisable to use the experimental points from interval b (for System I) or from intervals a and $b$ (for System II) only for the determination of the related equilibrium parameters, see Equations (12)-(18).

On the basis of known values for $\mathrm{V}_{\mathrm{d}}$ found in interval $\mathrm{d}$ for Systems I and II (see Table 1), the alkalinities: CAM(I) (Equation (3)), and CAM(II) (Equation (4)) can be calculated; obtaining:

$\mathrm{CAM}(\mathrm{I})=0.10078 \cdot 2.0122 / 4=0.0507$ (from Table 2, no. 1),

$\mathrm{CAM}(\mathrm{II})=0.10078 \cdot 2.4123 / 4=0.0608($ from Table 3, no. 3$)$.

\section{Final Comments}

This article provides the new consistent formulation for alkalinities referring to $\mathrm{NaHCO}_{3}+\mathrm{Na}_{2} \mathrm{CO}_{3}$ (System I) and $\mathrm{Na}_{2} \mathrm{CO}_{3}+\mathrm{NaOH}$ (System II) solutions, titrated with $\mathrm{HCl}$. The related formulae, specified in Table 2, are valid in defined $\mathrm{pH}$ intervals, denoted as b, c, d or a, b, c, d. The approach based on these new formulae has been called "carbonate alkalinity in a modified version" (CAM). All the formulae are closely relevant to the recently formulated total alkalinity (TAL) [1] [2]. The formulae for CAM are valid within defined $\mathrm{pH}$ ranges, in which the relationships between variables are expressed by the functions specified in Table 1.

The CAM approach enables equivalence volumes to be calculated, as well as the following physicochemical data: the activity coefficient $(\gamma)$ of hydrogen ions; the hybrid values for dissociation constants: $K_{1}^{*}, K_{2}^{*}$ for $\mathrm{H}_{2} \mathrm{CO}_{3}$, and $K_{W}^{*}$ for the ionic product of water. One of the main novelties of the method is the possibility of determining $\gamma$. Moreover, the common equilibrium constants: $\mathrm{K}_{1}, \mathrm{~K}_{2}$ and $\mathrm{K}_{\mathrm{W}}$ are also calculated. The possibility of calculating $\gamma$ is also inherent in the TAL method [1] [2]. Another interesting option is the determination of the related parameters in binary solvent media [6].

The $\mathrm{pH}$-intervals assumed for calculation of the analytical and physicochemical data are confined (see [2], p. 229 ) in comparison with the ones pre-assumed with use of the $\Delta=1.9$ value. The narrowing of the $\mathrm{pH}$-range taken for calculations results from the scale of $\left(\mathrm{C}_{01}, \mathrm{C}_{02}, \mathrm{C}\right)$ or $\left(\mathrm{C}_{02}, \mathrm{C}_{03}, \mathrm{C}\right)$ values applied in the experiments.

The procedure applied here can also be extended to salts other than carbonates. To extend the $\mathrm{pH}$ range covered by $\mathrm{pH}$ titration, it is suggested that the option involving the addition of a pre-dose is used [2]. When weak acid is considered, the strong base solution can be used as titrant or, after addition of the base as the pre-dose, the mixture can be titrated with a strong acid, as above.

The CAM method was tested experimentally. The results for the dissociation constants of $\mathrm{H}_{2} \mathrm{CO}_{3}$ are close to those found in literature [7]. The values for $\gamma$ are more scattered.

This article attempts to provide an introductory step for further studies about the determination of alkalinity

Table 2. Results obtained from repeated titrations made in System I.

\begin{tabular}{cccccccc}
\hline No. & $\mathrm{V}_{\mathrm{d}}$ & $\mathrm{V}_{\mathrm{c}}$ & $\mathrm{V}_{\text {eq1 }}$ & $\mathrm{V}_{\text {eq2 }}$ & $\gamma$ & $p K_{1}^{*}$ & $p K_{1}$ \\
\hline 1 & 2.0122 & 0.8017 & 0.4088 & 1.6034 & 0.928 & 6.379 & 6.351 \\
2 & 2.0152 & 0.8043 & 0.4066 & 1.6086 & 0.874 & 6.427 & 6.369 \\
3 & 2.0167 & 0.8046 & 0.4075 & 1.6092 & 0.891 & 6.453 & 6.403 \\
\hline
\end{tabular}

Table 3. Results obtained from repeated titrations made in System II.

\begin{tabular}{ccccccc}
\hline No. & $\mathrm{V}_{\mathrm{d}}=\mathrm{V}_{\text {eq2 }}+\mathrm{V}_{\text {eq3 }}$ & $\mathrm{V}_{\text {eq2 }}$ & $\mathrm{V}_{\text {eq3 }}$ & $\gamma$ & $p K_{1}^{*}$ & $p K_{1}$ \\
\hline 1 & 2.4096 & 1.5729 & 0.8367 & 0.8438 & 6.421 & 6.347 \\
2 & 2.4105 & 1.5703 & 0.8402 & 0.7978 & 6.459 & 6.361 \\
3 & 2.4123 & 1.5789 & 0.8334 & 0.7635 & 6.467 & 6.350 \\
\hline
\end{tabular}


according to the proposed TAL method [1] [2] for examination of natural, municipal and industrial waters, carbonated soft drinks and wines, as well as different biological systems.

The CAM presented here completes the list of modifications of the Gran methods presented in previously published articles [8]-[12], referring to different areas of titrimetric analysis.

\section{References}

[1] Asuero, A.G. and Michałowski, T. (2011) Comprehensive Formulation of Titration Curves Referred to Complex Acid-Base Systems and Its Analytical Implications. Critical Reviews in Analytical Chemistry, 41, 151-187. http://dx.doi.org/10.1080/10408347.2011.559440

[2] Michałowski, T. and Asuero, A.G. (2012) New Approaches in Modelling the Carbonate Alkalinity and Total Alkalinity. Critical Reviews in Analytical Chemistry, 42, 220-244. http://dx.doi.org/10.1080/10408347.2012.660067

[3] Pilarski, B., Dobkowska, A., Foks, H. and Michałowski, T. (2010) Modeling of Acid-Base Equilibria in Binary-Solvent Systems: A Comparative Study. Talanta, 80, 1073-1080. http://dx.doi.org/10.1016/j.talanta.2009.07.033

[4] Sayago, A., Boccio, M. and Asuero, A.G. (2004) Fitting Straight Lines with Replicated Observations by Linear Regression: The Least Squares Postulates. Critical Reviews in Analytical Chemistry, 34, 39-50. http://dx.doi.org/10.1080/10408340490273744

[5] Asuero, A.G., Sayago, A. and González, A. (2006) The Correlation Coefficient: An Overview. Critical Reviews in Analytical Chemistry, 36, 41-59. http://dx.doi.org/10.1080/10408340500526766

[6] Michałowski, T., Pilarski, B., Asuero, A.G., Dobkowska, A. and Wybraniec, S. (2011) Determination of Dissociation Parameters of Weak Acids in Different Media According to the Isohydric Method. Talanta, 86, 447-451. http://dx.doi.org/10.1016/j.talanta.2011.09.002

[7] Inczédy, J. (1976) Analytical Applications of Complex Equilibria. Horwood, Chichester.

[8] Michałowski, T., Baterowicz, A., Madej, A. and Kochana, J. (2001) An Extended Gran Method and Its Applicability for Simultaneous Determination of Fe(II) and Fe(III). Analytica Chimica Acta, 442, 287-293. http://dx.doi.org/10.1016/S0003-2670(01)01172-2

[9] Michałowski, T., Toporek, M. and Rymanowski, M. (2005) Overview on the Gran and Other Linearization Methods Applied in Titrimetric Analyses. Talanta, 65, 1241-1253. http://dx.doi.org/10.1016/j.talanta.2004.08.053

[10] Michałowski, T., Kupiec, K. and Rymanowski, M. (2008) Numerical Analysis of the Gran Methods. A Comparative Study. Analytica Chimica Acta, 606, 172-183. http://dx.doi.org/10.1016/..aca.2007.11.020

[11] Ponikvar, M., Michałowski, T., Kupiec, K., Wybraniec, S. and Rymanowski, M. (2008) Experimental Verification of the Modified Gran Methods Applicable to Redox Systems. Analytica Chimica Acta, 628, 181-189. http://dx.doi.org/10.1016/j.aca.2008.09.012

[12] Michałowski, T., Pilarski, B., Ponikvar-Svet, M., Asuero, A.G., Kukwa, A. and Młodzianowski, J. (2011) New Methods Applicable for Calibration of Indicator Electrodes. Talanta, 83, 1530-1537.

http://dx.doi.org/10.1016/.talanta.2010.11.067

\section{Symbols Used}

CAM—carbonate alkalinity $[\mathrm{mmol} / \mathrm{L}]$ in modified version;

$\mathrm{D}$ - titrand (solution titrated);

$\gamma=\mathrm{h} /\left[\mathrm{H}^{+}\right]$-activity coefficient for $\mathrm{H}^{+}$ions;

$\mathrm{h}$-activity of $\mathrm{H}^{+}$ions;

LSM-least squares method;

$\mathrm{pH}=-\log \left[\mathrm{H}^{+}\right]$;

$\mathrm{ph}=-\operatorname{logh}$;

T-titrant;

TAL—total alkalinity;

$\mathrm{V}$-volume $[\mathrm{mL}]$ of $\mathrm{T}$;

$\mathrm{V}_{0}$-volume [mL] of $\mathrm{D}$;

$\mathrm{V}_{\text {eqi }}$-volume [mL] of titrant, referring to the equivalence point $\left(\mathrm{V}_{\text {eqi }}, \mathrm{pH}_{\text {eq }}\right)$;

$[\mathrm{X}]$ - concentration $[\mathrm{mol} / \mathrm{L}]$ of the species $\mathrm{X}$. 
Scientific Research Publishing (SCIRP) is one of the largest Open Access journal publishers. It is currently publishing more than 200 open access, online, peer-reviewed journals covering a wide range of academic disciplines. SCIRP serves the worldwide academic communities and contributes to the progress and application of science with its publication.

Other selected journals from SCIRP are listed as below. Submit your manuscript to us via either submit@scirp.org or Online Submission Portal.
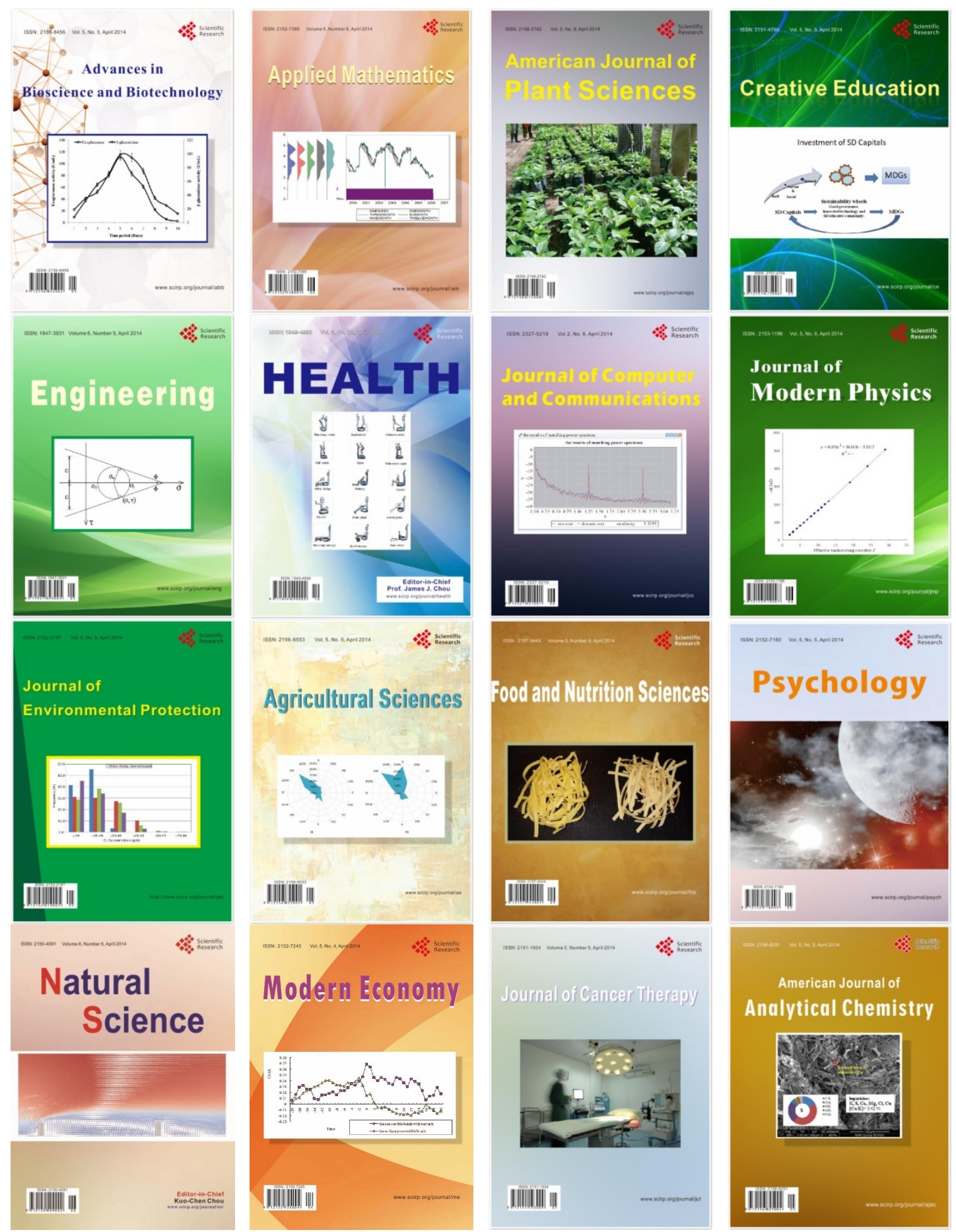